\title{
Re-interpretando os objetos de museu: da classificação ao devir
}

\author{
Re-interpreting museum objects: \\ From classification to becoming
}

Bruno BRULON ${ }^{1}$

\section{Resumo}

O presente texto tem o objetivo de introduzir uma reflexão sobre os enquadramentos tradicionalmente impostos aos objetos de museu questionando a sua sustentação empírica na Contemporaneidade. A vida museal do objeto, que acontece dentro ou fora das instituições formais, é produtora de diferentes enquadramentos classificatórios e informacionais. Estes, por vezes, os estigmatizam ligando-os às categorias criadas socialmente e que são cada vez mais percebidas como suplantáveis pelas Ciências Contemporâneas. Por meio de uma revisão bibliográfica detalhada, o artigo chama a atenção para uma mudança de percepção sobre os musealia em função, principalmente, de dois fenômenos distintos, quais sejam: (1) o novo sentido conferido ao objeto artístico pela Arte Contemporânea, atuando na reordenação dos enunciados sobre os objetos e os valores neles investidos; e (2) o advento dos ecomuseus, que relegam ao segundo plano do discurso museal os objetos materiais voltando-se para a musealização das relações do humano com o seu meio. Em ambos os casos, as categorias classificatórias que comportam os objetos nos museus tradicionais são perturbadas levando à concepção de uma nova categoria de pensamento que propomos chamar de objeto-devir.

Palavras-chave: Classificação. Informação. Museologia. Objeto-devir. Objetos de museu (musealia).

\begin{abstract}
The aim of the study is to reflect on the traditional frames imposed to the museum objects and question their empirical value in contemporary times. The life of museum objects, both inside and outside formal institutions, produces different classificatory and informational frames. These frames sometimes stigmatize the objects binding them to the socially created categories and are progressively perceived as transposable by Contemporary Sciences. By means of a detailed bibliographical revision, the paper calls attention to a change in perception on musealia due to two different phenomena, which are: (1) the new meaning attributed to the artistic object by Contemporary Art, reorganizing discourse about these objects and the value invested in them; and (2) the ecomuseum enterprise, that place material objects on the background of museum discourse, prioritizing the musealization of human relationships with the social environment. In both cases, the classificatory categories that describe traditional museum objects were disturbed, leading to the concept of a new thought category that we propose to call the object-becoming.
\end{abstract}

Keywords: Classification. Information. Museology. Object-becoming. Museum objects (musealia).

\section{Introdução}

O objeto, mais precisamente o de museu ou musealium, na nomenclatura estabelecida por Stránský
(1974), costuma ser remetido, no olhar do cientista contemporâneo, a um sistema de informações socialmente instituído para agrupar entidades individualizadas e lhes dar sentido. Um objeto pode ser um elemento de coleção

\footnotetext{
1 Universidade Federal do Estado do Rio de Janeiro, Centro de Ciências Humanas e Sociais, Departamento de Estudos e Processos Museológicos. Av. Pasteur, 458, Prédio CCHS, Sala 416, Urca, 24210-370, Rio de Janeiro, RJ. Brasil.E-mail: <brunobrulon@gmail.com>.

Recebido em 12/12/2014 e aceito para publicação em 25/3/2015
} 
ou parte de um conjunto sistemático mais amplo em vias de constituir um museu. Segundo Mairesse e Deloche (2011, p.389), se o objeto se refere a um conjunto organizado, a coisa é percebida, em geral, como "o mesmo elemento em seu contexto natural". É possível entender, como outros estudos já demonstraram (Bonnot, 2002, 2004; Appadurai, 2007), que uma coisa pode adquirir diferentes estatutos por meio de sua circulação entre e nas sociedades e de acordo com os diferentes sistemas de valores que atravessa. Nesse sentido, uma coisa se torna objeto na medida em que se insere em um sistema classificatório específico.

Para que a coisa ganhe o estatuto de objeto, ou para que um objeto de coleção passe a ser pensado como objeto de museu, um tipo de conversão deve ser operado pelo processo em cadeia da musealização. O objeto de museu - que não significa meramente o objeto em museu - como objeto musealizado, passa a adquirir um estatuto museológico. Tal conversão, do contexto ordinário da coisa ao universo simbólico do museu, implica um processo corolário de ressignificação para que o primeiro, detentor de sentidos em seu contexto precedente não-museal, adquira sentido no novo ambiente.

Tudo se passa como se a vida anterior à musealização deixasse de existir para que o objeto de museu possa"renascer" para um novo universo de significações. Nessa nova fase de sua existência são alterados, para além de sua função que deixa de ser utilitária e passa a ser interpretativa, os seus modos de se relacionar com os outros objetos e com os seres humanos que the dão sentido. Ele não perde a sua funcionalidade e nem mesmo é possível afirmar que "morre" para o mundo do qual fazia parte anteriormente, no entanto, deixa de exercer as suas funções tradicionais para ser interpretado como símbolo ou signo (Pearce, 2006) de realidades sociais específicas (reais ou imaginadas).

Essa vida museal do objeto, que acontece dentro ou fora das instituições formais, é produtora de diferentes enquadramentos classificatórios e informacionais que, por vezes, os fixam, congelam, estigmatizam ligando-os às categorias criadas socialmente e que são cada vez mais percebidas como transitórias, imprecisas e suplantáveis pelas ciências contemporâneas. A problematização do objeto teve como antecedentes fenômenos que levantam questões e propõem uma reconfiguração da forma pela qual os museus e os cientistas que neles atuam pensam as classificações. A démarche da Arte Contemporânea, por exemplo, questionadora da própria ontologia da "obra de arte", por um lado, e o advento dos ecomuseus, apresentando novos entendimentos sobre a musealização in situ, por outro, podem ser apontados como responsáveis por abalar as estruturas do sistema de significações em que os musealia são comumente inseridos.

\section{Procedimentos metodológicos}

\section{Um outro olhar sobre a classificação museológica}

Por meio da revisão bibliográfica detalhada, este texto introduz uma reflexão sobre os enquadramentos tradicionalmente impostos aos objetos de museu questionando a sua sustentação empírica na Contemporaneidade e propõe um outro olhar sobre eles enxergando a relativização do conhecimento e da sua classificação. A breve análise do campo museal aqui apresentada tem por finalidade discutir a especificidade mesma dos objetos que adentram esse ambiente e entender, a partir de diferentes correntes de pensamento que tangenciam a teoria do objeto aplicada à Museologia, como se dão os processos de produção de sentido e de valores nesses casos.

Durante o vasto período em que os museus tradicionais na Europa estabeleciam para quase todo o mundo um padrão para a organização do conhecimento produzido pelas disciplinas científicas estabelecidas, a entrada de um objeto na cadeia museológica (Brulon-Soares, 2012) representava, inevitavelmente, a sua afiliação a uma ou outra corrente disciplinar. Tal conexão visceral do objeto à disciplina responsável por sua coleta, interpretação e documentação propicia a sua "consagração mágica", nas palavras de Bourdieu (2009, p.123), que lhe confere efeitos simbólicos no contexto museal.

Diversos são os termos aceitos para se referir à "peça individual" (Pearce, 2006) ou ao conjunto de peças que compõem o material cultural dos museus. "Objeto", "coisa", "espécime", "artefato"e"bem"(ou"bens"), além dos termos gerais"cultura material"e"patrimônio", fazem parte da terminologia comum a esse meio. Os termos citados compartilham o fato de se referirem a partes do mundo 
físico às quais são atribuídos valores culturais específicos (Pearce, 2006, p.9). No entanto, as pequenas variações terminológicas denotam diferenças de significados que se dão em função das distintas tradições disciplinares das quais provém cada um dos vocábulos.

Como lembram Mairesse e Deloche (2011, p.391), no século XIX um vocabulário específico para classificar objetos pela arqueologia e a história da arte já estava estabelecido no campo dos museus: para além dos termos"quadros", "estátuas", etc., outros como "antiguidade" ou "obras de arte" ainda são frequentemente utilizados para se referir às obras presentes nos museus desse período. Com efeito, a história da arte se legitimou como disciplina por meio da valorização dos objetos pertencentes ao seu domínio de estudos como documentos únicos cuja autenticidade era reconhecida.

Por outro lado, no momento da criação dos primeiros museus de etnografia a partir do final do século XIX e ao longo de grande parte do século XX, a busca por testemunhos materiais do homem e de seu meio desempenhava um papel fundamental no desenvolvimento das pesquisas etnográficas. Foi o acúmulo e a organização dos objetos da cultura material de diferentes sociedades nos museus europeus e em alguns das colônias que levou a antropologia a se legitimar como disciplina científica reconhecida. Nesses locais, que guardavam os testemunhos da colonização, a etnologia - ou antropologia, como passaria a ser chamada - se baseava na importância da produção documental sistemática por meio da classificação dos "objetos-testemunho" organizados em séries lógicas e identificados por uma numeração, um título de inventário, uma descrição, desenhos, fotos, função original e os demais dados levantados pelo etnólogo.

Outros tipos de instituições ainda apresentavam modelos classificatórios variantes. Por sua vez, a perspectiva dos museus de ciência, que se desenvolveu em paralelo às demais, privilegiou a coleta de "espécimes" para estudar "tipos". Assim, os métodos de nomenclatura criados e adotados até hoje para classificar certos espécimes biológicos foram formulados por meio da sua seleção e organização em coleções ou museus. Para essas instituições, a função de comunicação e de educação assume o primeiro plano na medida em que é ressaltada a importância do acesso às ciências naturais e a sua compreensão.
Essas disciplinas, e os museus que abrigavam suas coleções, foram responsáveis não por criar apenas nomenclaturas ou categorias classificatórias no seio das instituições, mas os próprios objetos de museu ao nomeá-los e classificá-los. Tal reflexão, permite identificar como as categorias tradicionais estavam atreladas a uma museologia específica, ligada aos sistemas de organização do conhecimento moderno.

A classificação, ao longo da história dos museus, se impôs como uma prática que visava a comparação de objetos de natureza ou origem distintas. Sua introdução na cadeia museológica se deu por influência das ciências da natureza. A zoologia e a anatomia macroscópica forneceram os primeiros modelos para o método comparativo que seria introduzido nas ciências sociais (Barth, 2000). Comparar, no século XIX, constituía uma parte necessária do trabalho investigativo nos muséums de história natural e nos primeiros museus de etnografia. Atualmente, no caso dos museus em que comparações ainda são realizadas entre objetos da cultura material, estas acabam tendo cada vez menos validade empírica considerando tratar-se de comparações subjetivas entre interpretações.

Em geral, os objetos da cultura material representam um fragmento do meio ambiente humano que é "intencionalmente moldado pelo homem segundo um plano cultural determinado" (Pearce, 2006, p.9). Esse processo intencional, como ressalta Pearce (2006, p.10), pode transformar objetos "naturais" em peças da cultura humana. Tal afirmação significa, para os estudos de cultura material, que mesmo uma coleção de história natural em um museu pode ser estudada nos termos da disciplina e entendida como cultura. Para a Museologia, ela implica na compreensão da musealização e dos enquadramentos classificatórios que ela abarca, como um processo social e culturalmente determinado.

Ao se ater restritivamente à dimensão documental dos objetos, a perspectiva informacional vem se mostrando insuficiente para explicar as categorias e classificações utilizadas para organizá-los em conjunto nos museus. Por vezes, ela deixa de considerar o caráter sociocultural das categorias construídas nos processos de musealização, bem como o seu entendimento como enunciados performativos (Bourdieu, 2009), o que permitiria a compreensão da sua eficácia simbólica. A criação 
de uma categoria e a implementação de um sistema classificatório, no entendimento das trocas linguísticas proposto por Bourdieu (2009), aspiram alcançar o limite de todos os "enunciados performativos" (Bourdieu, 2009, p.20). A categoria faz existir aquilo que anuncia e, nesse sentido, é a classificação que cria a classe e não a informação.

Tal abordagem torna evidente, através de uma sociologia das classificações, a natureza social dos rótulos e indexadores em um museu. Em meio ao ritmo real das disputas simbólicas, as lealdades são construídas nas narrativas museológicas e confusões epistêmicas e práticas começam a tomar forma quando os objetos musealizados se mostram "vivos demais" para as categorias que habitam.

\section{Resultados}

\section{Propondo a noção de objeto-devir}

Os objetos de museu escapam sensivelmente às categorias que lhes são impostas pela museologia tradicional. Em diversos aspectos, os museus e a museologia do presente já não são os mesmos que construíram uma imagem estigmatizada da instituição e dos seus objetos no passado. Definidos no bojo do lluminismo pelo paradigma Newtoniano-Cartesiano, que compartimentou o conhecimento, esses locais, no passado, se apresentavam de acordo com modelos conceituais bem definidos. Hoje, segundo uma perspectiva relativista sobre as ciências, nenhum museu pode ser definido apenas pelo conhecimento transmitido por suas coleções ou pelo modo adotado para organizá-las e apresentá-las a um público determinado. O campo museal não se vê mais fragmentado ou compartimentado cartesianamente, mas integrado segundo uma cadeia de apropriações sobre objetos e discursos que leva alguns autores a pensarem em "canibalismos disciplinares" (Dufrêne \& Taylor, 2009, p.8) no seio dessas instituições.

Ao reconhecerem em suas coleções, ou na própria forma de apresentação dos objetos, uma possível relativização da disciplina-mãe que os reuniu, os museus do presente veem-se diante do impasse de serem seduzidos, ou pela linguagem da neutralidade estética, por meio da qual diversas apropriações disciplinares são possíveis, ou, em uma abordagem simetricamente diferente, pela contextualização integral de seus objetos, mantendo-os em seu contexto original para que continuem a agregar sentidos e significados de maneira ampla. Nos dois casos, as diferentes disciplinas, antes bem organizadas em vitrines complexas, canibalizam umas às outras para produzir um discurso acessível a diversas visões de mundo.

Progressivamente, os sistemas de classificação vêm sendo alterados em benefício das relações que um mesmo objeto pode estabelecer com diferentes disciplinas ou abordagens museológicas. Uma parte da Arte Moderna, depois de Marcel Duchamp, por exemplo, se estruturou em reação às noções - já mencionadas como legítimas nos museus do século XIX - de "obra" e"obra de arte" a tal ponto de descreditar esses rótulos libertando a arte do presente. A capacidade de uma "obra" transitar simultaneamente no universo museal e em diversos outros universos sociais - como o utilitário ou o ritual - faz com que objetos que integram uma coleção possam facilmente retornar ao circuito de que faziam parte antes da musealização, colocando em questão as teorias rígidas sobre sua passagem à arte ou a musealium.

O campo da Arte não demorou a reconhecer que os objetos, ao passarem pela musealização, não se encontram necessariamente cristalizados ou reificados em seu novo estatuto, podendo ser muito facilmente remobilizados nos dispositivos culturais (Notteghem, 2012, p.59). O mesmo pôde ser constatado, na museologia dos últimos anos, com os ecomuseus ou os museus comunitários, onde se instaura um tipo de processo que permite que os objetos do cotidiano pertençam simultaneamente a dois mundos. Ao colocarem em prática um tipo de musealização dos contextos e não só dos objetos, os museus comunitários estabelecem uma concepção do objeto para além das fronteiras classificatórias. Nos ecomuseus, o objeto de uso, que se manipula, se quebra, é recuperado e passa a fazer parte de um ritual; ele é apreendido e apropriado segundo a noção de objetodevir que aqui será proposta para romper com a unidade simbólica do objeto, percebida como a base lógica de algumas dessas instituições.

Atualmente, pode-se inferir que o culto à "documentalidade", identificado a partir dos anos 1960 por 
autores que pensavam a Museologia pelo viés da Ciência da Informação (Maroević, 1983; Šola, 1992; Van Mensch, 1992), deixou de constituir a raison d'être do culto aos objetos de museu. Em parte, tal mudança, que toca diretamente o coração da relação sujeito-objeto fundadora dessas instituições, ocorreu devido à transformação na gramática museológica, a qual tradicionalmente colocava em primeiro plano as próprias coleções e seu valor documental e agora passa a privilegiar o valor das experiências humanas a partir das diversas possibilidades interpretativas sobre os objetos.

Progressivamente, a Museologia Contemporânea esgotou as suas formas objetivas buscando explorar na subjetividade dos visitantes a sua principal instância de atuação. A transição se deu, principalmente, por dois fenômenos distintos que se desenvolveram em paralelo na história contemporânea dos museus, quais sejam: (1) o novo sentido conferido ao objeto artístico pela arte contemporânea atuando na reordenação dos enunciados sobre os objetos e os valores neles investidos, sobretudo nas instituições não introduzidas à linguagem artística clássica; e (2) o advento dos ecomuseus, que, em particular na França, a partir da década de 1970, se propõem a relegar ao segundo plano do discurso museal os objetos materiais e se voltam para a musealização das relações do humano com o meio. Em ambos os casos, as categorias classificatórias que comportavam os objetos nos museus são perturbadas.

Com base em estudos voltados para a Sociologia dos valores investidos à arte, é possível afirmar que a arte contemporânea representa a estruturação de um novo paradigma para o campo artístico. Segundo Heinich (2014, p.15), ela já pode ser percebida hoje como formadora de um mundo altamente coerente, mas "em ruptura radical com as expressões de arte familiares ao grande público"e mesmo àquele cultivado. Em particular, a discussão sobre o estatuto da obra e sua classificação como arte fazem parte do domínio da arte contemporânea desde que esta passou a ser concebida, rompendo com os padrões das artes clássica e moderna.

Por outro lado, foi o surgimento dos ecomuseus que permitiu a musealização integral dos objetos e dos valores que thes são atribuídos pelas pessoas, promovendo a manutenção das relações sociais. Nesses museus não há uma acepção disciplinar única possível e os mo- delos preconcebidos são substituídos pelo conjunto de questões e problemas dos quais tanto as pessoas quanto os objetos são testemunhos. O processo de criação dos ecomuseus tratou de um alargamento progressivo do campo nocional dos objetos do patrimônio avaliados e/ou valorados pelas populações como "objeto de museu". Na maior parte dos casos, o trabalho desenvolvido nessas instituições tratou de permitir aos habitantes locais deixarem de interpretar os seus próprios bens a partir de um sistema de valores disseminado pelas elites das metrópoles culturais para interpretá-los de acordo com os seus próprios e a sua auto avaliação mediada pelos agentes do museu.

Essas experiências que subvertem a relação tradicional entre o objeto e o olhar do observador já povoam o imaginário do público e geram problemas incontornáveis para os pesquisadores. Assim, reconhece-se, como sugere Heinich, que mais do que qualquer outra ação"o 'olhar' não é, ele mesmo, observável a olho nu', e só se permite ser abordado por meio da sua verbalização (Heinich, 2009, p.135). O objeto olhado é continuamente prisioneiro das palavras que o descrevem ou que o interpretam, constituindo simultaneamente documento de si mesmo e devir. Para melhor explorar tal noção aplicada aos objetos de museus, pode-se remeter à ideia de devir disseminada por Deleuze e Guattari (2009), a qual referese às relações estabelecidas entre subjetivações, totalizações ou unificações que são produzidas a partir de multiplicidades. Nesse sentido, falar em objeto-devir significa fazer referência não mais ao objeto em si, mas às relações que configuram sua existência social.

Na prática dos processos de musealização, tal perspectiva implica em perceber "a informação cultural não como ligada à classe de informação científica", mas entendendo-a como demasiadamente variável; ela aparece e desaparece, de acordo com o sistema de valores ao qual está vinculada (Maroević, 1997, p.121). O objeto de museu, assim, é uma "permuta de significados" e o trabalho sobre as coleções em um museu só tem sentido se colocado em relação com o campo de pesquisa, onde o objeto constitui o "pré-texto" (Jamin, 1984, p.48). Ele é, de fato, a base do que irá se escrever como discurso, e a sua contextualização depende, em primeiro lugar, da descontextualização dos múltiplos conceitos produzidos sobre ele. 


\section{Discussão}

\section{Desafiando os limites da classificação}

A perspectiva sociológica aqui apresentada exclui a possibilidade da crença na imparcialidade e na objetividade dos museus. Constatou-se assim, que os museus atuam sobre os mundos sociais que apresentam e não apenas se alimentam deles. Isso não significa que as instituições do presente são levadas a abandonar progressivamente todas as formas de classificação; o que elas colocam em prática é uma mudança no sistema de valores no qual elas são construídas. O campo museal atravessa uma transformação axiológica, isto é, os critérios elencados para levar um objeto a ser reconhecido como "objeto de museu" estão sendo revisados.

Mesmo com a invenção subjetiva da experimentação "livre" da obra de arte, colocada em prática pelos agentes da arte contemporânea, não se pode perder de vista a historicidade dessa experiência (Bourdieu, 1998, p.466). Ao ser comentada por críticos e entrar para um museu, a arte "livre" é instituída e normatizada:

Le musée, qui isole et sépare (frames apart), est sans doute le lieu par excellence de l'acte de constitution, continûment répété, avec la constance inlassable des choses, à travers lequel se trouvent affirmés et continûment reproduits et le statut de sacré conféré aux œuvres d'art et la disposition sacralisante qu'elles appellent. (Bourdieu, 1998, p.478, grifos do autor)2.

A exposição de objetos em uma instituição de arte, nesse sentido, é uma forma de controle e retenção do poder neles investido. A arte ocidental é levada, então, a servir como ferramenta para tratar coisas diferentes de maneira igual. E é assim que ela vem sendo usada, por exemplo, nos museus que expõem arte primitiva no Ocidente. Ao se alastrar por instituições que mantêm coleções as quais escapam historicamente à classificação da "obra de arte", a linguagem artística contemporânea permitiu aos museus de arte primitiva libertarem as coleções de objetos etnográficos do peso simbólico da colonização, de modo que alguns antropólogos, atualmente, se distanciam do campo do simbólico para pensar os objetos dentro de um campo da ação (Gell, 1998).

Uma exposição no Musée Dapper, em Paris, em 2011, demonstrou como a arte permite unir objetos distintos em um mesmo espaço, inseridos em uma mesma linguagem e evocando uma mesma 'crença'. A exposição denominada "Mascarades et Carnavals" (Mascarados e carnavais) organizada pela instituição, mistura objetos rituais, adereços de carnaval e objetos de arte popular, sem fazer nenhuma distinção entre estas que seriam categorias antropológicas por excelência. "Quais são os laços entre as máscaras da África subsaariana e as produções carnavalescas das sociedades caribenhas?", se pergunta o museu sobre os objetos escolhidos para a exposição Musée Dapper - 2011. A pergunta, colocada no texto escrito para o folheto de divulgação, não tem outra resposta exceto a da arte como categoria englobante. Usando uma linguagem expositiva, a qual trata de maneira análoga ritos de iniciação e festas populares, o museu ressalta as características artísticas dos objetos apresentados, tanto da África quanto da América, sem deixar de fazer referência (através de vídeos etnográficos ou textos breves) aos seus usos - mas explicitando que não é deles que se trata aquela mise en scène.

A entrada de artistas indígenas para o universo seleto dos artistas contemporâneos reconhecidos pelos museus e pelo mercado só foi possível graças à especificidade mesma da arte contemporânea, em relação aos outros períodos que organizam a arte do Ocidente. Ainda que se apresente uma crise das fronteiras historicamente construídas pelos museus para organizar os seus objetos, não se pode deixar de notar que as novas categorias classificatórias adotadas resultam de disputas simbólicas que já não são as que levaram à constituição dos museus de arte clássica ou dos de etnografia. Um novo terreno de negociações se apresenta, onde objetos do passado precisam ser ressignificados para adquirir valor no presente. Tais disputas, entretanto, não são em geral sobre o que será representado, mas sobre quem controla os meios de representação (Karp \& Lavine, 1991). Os embates pela imposição de uma visão de mundo estão tão presentes nos grandes museus de arte da Europa quanto nos

\footnotetext{
2 "O museu, que isola e separa (frames apart), é, sem dúvida, o lugar, por excelência, do ato de constituição, continuamente repetido, com a constância incansável das coisas, através do qual estas se encontram afirmadas e continuamente reproduzidas e o estatuto de sagrado é conferido às obras de arte assim como a disposição sacralizante que elas demandam" (tradução minha).
} 
museus comunitários, desenvolvidos por habitantes que não compartilham dos códigos culturais das elites cultivadas.

Os ecomuseus também foram responsáveis por abalar as concepções construídas histórica e socialmente sobre a axiologia dos musealia, ao demonstrarem que os objetos de um museu também circulam e ao circularem agregam novos valores sem necessariamente perder aqueles agregados em outros sistemas de trocas que compõem a sua biografia. Ao analisar esse processo de valorização das sobras da indústria na região do Creusot, Bonnot (2002) chama a atenção para a transformação pela qual atravessaram os objetos banais das indústrias na França a partir dos processos de musealização que tiveram início com os ecomuseus da região. Ele aponta que artigos de cerâmica produzidos na usina de Langeron, fechada em 1957, expostos em 1974, em um dos primeiros eventos do tipo do jovem ecomuseu da comunidade Le Creusot-Montceau-les-Mines, são elevados ao estatuto de elementos do patrimônio,"no mesmo título que as cartas medievais, os utensílios arcaicos e outras esculturas" (Bonnot, 2002, p.3). Esses objetos banais, produtos de um passado recente, eram apresentados sinuosamente nessa exposição que marcava uma mudança simbólica fundamental para o entendimento do campo museal no presente.

A significação do objeto é uma das noções colocadas em causa pela perspectiva biográfica adotada por Bonnot (2004). Segundo o autor, mais do que o objeto em si mesmo, é evidentemente o seu estatuto social e simbólico e a interpretação de seus manipuladores que se enriquecem e se adicionam às representações das quais ele foi suporte a partir da sua produção física. Nessa abordagem, é impossível pensar em cristalização ao se evidenciar o caráter processual dessas significações e a ilusão do objeto como entidade fixa. Ao entrar em um novo quadro de valores, o objeto adquire uma mais-valia simbólica que passa a caracterizá-lo, entre outras coisas, como alvo do desejo de colecionadores e amantes das artes.

Os ditos museus sociais, que já deixam de ser vitrines da etnologia passando pela reapropriação das populações locais, têm o papel de interrogar os objetos na sociedade, não somente como utensílios, produtos ou obras. O objeto não é somente mediador na difusão de conhecimento pelo museu - objeto-testemunho-ele o é igualmente na interação social cotidiana. O que se propõe com a perspectiva biográfica é a concepção dos objetos como portadores de socialidades, o que permite considerar que as diversas categorias atribuídas a eles não passam de rótulos momentâneos que refletem um estado do objeto, mais do que a sua ontologia.

A ecomuseologia não pretendia simplesmente que as coisas fossem mantidas'em seus lugares', mas que os contextos fossem mantidos às coisas. Nesse sentido, pouco importa se se está falando de objetos de arte ou de monumentos históricos - pois um objeto no seio de uma comunidade é simultaneamente obra de arte, testemunho histórico, objeto etnográfico e, logo, objeto- devir. Trata-se de manter os objetos atrelados àquilo que Ihes dá sentido - seja a mão de um trabalhador ou o olhar contemplativo do grupo social.

\section{Conclusão}

A realidade empírica dos objetos classificados pelos museus por muito tempo deixou de considerar as constantes transformações no campo do observado, priorizando as concepções criadas na mente do observador. Atualmente, o processo de desmaniqueização da realidade social, decorrente da própria redefinição das ciências sociais, ganha força e se espalha entre as demais disciplinas que povoam os museus. No entanto, pode-se questionar até que ponto essas instituições vêm assimilando a relativização dos sistemas cognitivos produtores das categorias que utilizam, bem como até onde continuam a reproduzir modelos classificatórios que percebem os objetos meramente como portadores de informações objetivas achatando a gama de significados culturais que lhes podem ser socialmente atribuídos.

Na realidade atual do campo museal, o fato de um objeto fazer parte de uma coleção de museu não significa que ele será facilmente identificado como "obra de arte", "objeto-testemunho" ou "espécime" científico. Ainda que as categorias classificatórias não tenham se tornado obsoletas, seu uso passa a ser relativizado de acordo com as culturas de onde o objeto provém, a intenção dos seus produtores ou os interesses daqueles que Ihe atribuíram valor. Tal relativização dos processos classificatórios permite aos museus 'brincar' com os seus próprios enunciados e produzir novos efeitos simbólicos a partir dos mundos de significação e interpretação. 
Em ambos os casos, nos museus de arte, onde se impõe a neutralização das vidas pregressas dos objetos, ou nos ecomuseus, onde a musealização implica na manutenção das relações sociais em contexto, a instituição realiza um ato de consagração de um estado de coisas e de uma dada ordem sobre a realidade musealizada. Segundo a axiologia vigente, a consagração museal, ao invés de sancionar as categorizações, liberta o objeto das classificações tradicionais para torná-lo disponível às múltiplas interpretações do público. Na prática, ao invés de se tornar obsoleta, a documentação museológica ganha ênfase, cabendo a ela o papel de documentação histórica e sociológica, registrando todos os estados do objeto e as relações estabelecidas em sua biografia.

Como consequência, hoje é função da Museologia não apenas voltar-se aos objetos e à informação atribuída a eles (seja ela artística, histórica, etnográfica ou científica), mas dedicar parte da pesquisa ao estudo das culturas em que os sistemas de informação são fabricados. A Museologia, então, tem o seu foco de estudo radicalmente ampliado, passando do que há de intrínseco aos objetos precisamente classificados, ao que há de devir nas múltiplas interpretações lançadas sobre eles.

\section{Referências}

Appadurai, A. Introduction: Commodities and the politics of value. In: Appadurai, A. (Ed.). The social life of things: Commodities in cultural perspective. Cambridge: Cambridge University Press, 2007. p.3-63.

Barth, F. Metodologias comparativas na análise dos dados antropológicos. In: Lask, T. (Org.). O guru, o iniciador, e outras variações antropológicas: Fredrik Barth. Rio de Janeiro: Contra Capa, 2000. p.187-200.

Bonnot, T. La vie des objets: d'ustensiles banals à objets de collection. Paris: Éditions de la Maison des sciences de l'homme, 2002.

Bonnot, T. Itinéraire biographique d'une bouteille de cidre. L'homme, n.170, p.139-164, 2004.

Bourdieu, P. Ce que parler veut dire: l'économie des échanges linguistiques. Paris: Fayard, 2009.

Bourdieu, P. Les règles de l'art: genèse et structure du champ littéraire. Paris: Éditions du Seuil, 1998.

Brulon-Soares, B.C. Máscaras guardadas: musealização e descolonização. 2012. Tese (Doutorado em Antropologia) Programa de Pós-Graduação em Antropologia, Universidade Federal Fluminense, Niterói, 2012.

Deleuze, G.; Guattari, F. Mil Platôs: capitalismo e esquizofrenia. Rio de Janeiro: Ed. 34, 2009.

Dufrêne, T. ; Taylor, A.-C. (Org.). Cannibalismes disciplinaires: quand l'histoire de l'art et l'anthropologie se rencontrent. Paris: Musée du quai Branly, 2009.

Gell, A. Art and agency: An anthropological theory. Oxford: Clarendon Press, 1998.

Heinich, N. La fabrique du patrimoine: de la cathédrale à la petite cuillère. Paris: Éditions de la Maison des sciences de I'homme, 2009.

Jamin, J. Aux origines du Musée de l'Homme: la mission ethnographique et linguistique Dakar-Djibouti. Cahiers Ethnologiques, n.5, p.7-73, 1984.

Karp, l.; Lavine, S.D. (Ed.). Exhibiting cultures: The poetics and politics of museum display. Washington and London: Smithsonian Institution Press, 1991.

Mairesse, F.; Deloche, B. Objet [de musée] ou muséalie. In: Desvallées, A.; Mairesse, F. (Ed.). Dictionnaire encyclopédique de muséologie. Paris: Armand Colin, 2011. p.385-419.

Maroević, I. Museology as a part of information sciences. ICOFOM Study Series, n.5, p.43-46, 1983. Available from: <icofom.icom.museum>. Cited: Nov. 12, 2014.

Maroević, I. The museum object as a document. ICOFOM Study Series, n.23, p.113-120, 1994. Available from: <icofom. icom.museum>. Cited: Nov. 12, 2014.

Maroević, I. The role of museality in the preservation of memory. ICOFOM Study Series, n.27, p.120-125, 1997. Available from: <icofom.icom.museum>. Cited: Nov. 12, 2014.

Notteghem, É. Frontières et franchissements: les objets du culte catholique en artification. In: Heinich, N.; Shapiro, R. (Ed.). De l'artification: Enquêtes sur le passage à l'art. Lassay-lesChâteaux: Éditions de l'École des Hautes Études en Sciences Sociales, 2012. p.47-62.

Pearce, S.M. Objects as meaning, or narrating the past. In: Pearce, S.M. (Ed.). Interpreting objects and collections. New York: Routledge, 2006. p.19-29.

Šola, T. A contribution to a possible definition of museology. Paris, 1992. Available from: <www.heritology.com>. Cited: Mar. 82014

Stránský, Z.Z. Metologicke otazky dokumentace soucasnosti. Muzeologicke Sesity, n.5, p.13-43, 1974.

Van Mensch, P. Towards a methodology of museology. 1992. Thesis (Doctorate in Museology) - Information Science Program, University of Zagreb, Zagreb, 1992. 
